have endeavoured to avoid invoking unusual complications in the terminology. Instead, I have followed the idea of a classification which can connote mutually affected characteristics of both the firn pack and its underlying ice as a stress-influenced total system. (The stress here could be climatological or kinetic, or both.) As for strict considerations in glacier dynamics the main interest would be in deformation and mass transfer of the deep ice. I believe that the suggested classification does indeed lend itself to this, with any pertinent subsidiary characteristics, say in the bottom zone, being best considered not by single terminology but by appropriate modifying comments to be appended to the framework categories of the suggested classification.

G. K. C. Clarke: I would like to speak on behalf of preserving a certain vagueness in terminology. It seems to me that the use of highly specific terms to describe the thermal structure of a glacier can be abused to imply that you have more information than your measurements support.

Miller: I agree, to the extent that the classification which I have discussed does retain a certain desired looseness. As for implying more information than one has, this danger is implicit in the use of any descriptive phraseology. There will always be a need for scientific integrity in any reporting endeavour. But I am not too concerned about the danger of muddying the scientific waters too much here because after all the presentation of facts is what is judged. Perhaps if we are not sure at all of what the thermal character of a glacier system is we could indeed call it "crypto-thermal"!

\title{
THE SPEED OF GLAGIERIZATION OF CANADA DURING THE WISCONSIN ICE AGE
}

\author{
By M. W. Mahaffy and J. T. Andrews \\ (Institute of Arctic and Alpine Research, University of Colorado, Boulder, Colorado 80302, \\ U.S.A.)
}

Abstract. A three-dimensional, time-dependent numerical model of ice sheets, developed by Mahaffy (unpublished), has been applied to the general problem of the speed of ice-sheet inception and development over Canada during the last major glaciation. Ice sheet development is assumed to begin due to a lowering of the equilibrium-line altitude with a resulting increase in the accumulation over Baffin Island and Laborador in Canada. This leads to the development of large snow fields over the high plateau areas of this region. Preliminary results are given for the areal extent and the water volume of the ice sheets possible after a period of 10000 years from the initiation of glaciation.

\section{REFERENGE}

Mahaffy, M. W. Unpublished. A three-dimensional numerical method for computing the load distribution of ice sheets with time. [M.S. thesis, University of Colorado, 1974.]

\section{DISGUSSION}

J. W. Glen: How was the sea-level change calculated? Did you assume no changes in ice volume anywhere else in the world? 
M. W. MAHAFFY: The sea-level change shown was just that change due to the ice sheets built up by the model over Baffin Island and Labrador. Although the mass contribution due to Scandinavia would probably be relatively small compared with this, the added mass over Greenland could probably increase this sea-level drop considerably.

W. H. Mathews: Were any other centres of glacial growth, e.g. west of Hudson Bay, considered?

MAHAFFY: Yes, under the specific net budget function assumed, no ice accumulated there because the topography was too low.

Mathews: Why did your modelling cease at $\mathrm{r}$ o ooo years instead of continuing until a cap comparable in size to the Laurentide ice sheet was developed?

MAHAFFy: This was not an attempt to model reality. This was an attempt to maximize the ice accumulation over the area. I feel we could spend our computer funds better on a complete build-up model if we attempt to match the field data better.

Mathews: In your model for Baffin Island after io ooo years all of Baffin Island was ice covered. But Andrews points out that areas escaped (the last) glaciation along the east coast (e.g. Cape Dyer). Should a more sophisticated model be considered with greater accumulation rate on the west slope compared with the east?

MAHAFFY: Yes, this would be the more realistic model of the ice-sheet build-up that I spoke of. It would be much less likely to match the sea-level drops needed, but would give a much clearer picture of the ice-sheet loads and areal extent through time.

F. MüllER: It would be worthwhile to try and take into account the very important backcoupling effects of the changes in the surroundings of the growing ice caps, such as albedo changes due to longer snow seasons and increasing size and number of perennial snow patches, or the decreasing supply of moisture due to increasing distances to moisture source areas as the regional lake- and sea-ice cover grows.

G. Holdsworth: Would you expect to get a qualitative check for your derived ice-cap shape from the deglaciation sequence map of Prest ( 1969 )?

MAHAFFY: Yes, this would be a good qualitative check on the more realistic build-up model we have been discussing. One of the main projects I am now working on is the deglaciation of the Laurentide ice sheet for which I am using Prest's deglaciation maps extensively.

Holdsworth: Of course I was assuming your model would work in reverse. There are too many other factors (mainly climatic) which would preclude dealing with the build-up phase in this way.

C. F. RAYMond: Did you use a simple forward difference in time and what stability problems did you run into?

Mahaffy: The difference scheme used here was an Alternating Direction Implicit scheme, which is a time-centered scheme. It approximates the Crank-Nicholson equation. A simple explicit scheme was very unstable for these equations. The ADI scheme used here is not unconditionally stable due to the non-linearity of the equations. However, they were more stable than accurate, and my time-step criterion was not limited by stability but rather by the accuracy of the scheme.

L. Lliboutry: How do you ignore temperature considerations? I am not convinced that $A$ and $n$ could be considered as constants with time.

MAHAFFy: The temperature parameter, $A$, is an average value of $A$, weighted toward the bottom layers where most of the strain occurs. For this initial run, $A$ and $n$ were taken rather high and held constant in order to maximize the height build-up of the ice sheets. Ordinarily you would expect the average value of $A$ to drop during the build-up of a large ice sheet as 
frictional heating took over. The value of $n$ would start as a low value, increasing with the increase in ice thickness until a good-sized sheet had been build up, then would probably change very little with time until the ice sheet began to waste appreciably.

J. F. Nye: The equations you are using seem to imply that at the edge of the ice sheet, where the thickness is zero, the outward velocity of the ice is automatically zero. This follows essentially because the sliding velocity is held at zero (and provided the surface slope is not allowed to be infinite). Thus the equations do not allow the ice sheet to expand in size, even though this is what you deduce. Thus, strictly speaking, your results are inconsistent with your equations. However, I imagine that this difficulty can be fairly easily removed by some suitable readjustment of the model in a zone very close to the ice edge. Then probably your results would not be seriously affected. Do you agree?

MaнAFFY: In fact, the finite-difference scheme used tacitly assumes that the mass discharge across the edge is not zero, but is equal to the mass discharge calculated at the previous point. This is equivalent to a boundary condition of a sliding velocity at the edge that is small but finite. You are right in pointing out that, at the edge, this finite-difference scheme does not approximate the analytic equations with a sliding velocity equal to zero.

\title{
REFERENCE
}

Prest, V. K. 1969. Retreat of Wisconsin and Recent ice in North America. Canada. Geological Survey. Map $1257 \mathrm{~A}$.

\section{NEAR-SURFAGE TEMPERATURES IN THE SUPERIMPOSED ICE ZONE AND LOWER PART OF THE SOAKED ZONE OF POLAR ICE SHEETS}

\author{
By Roger LeB. Hooke
}

(Department of Geology and Geophysics, University of Minnesota, Minneapolis, Minnesota 55455 , U.S.A.)

Abstract. The temperature distribution in a polar glacier is described by the equation of heat conduction,

$$
\kappa \nabla^{2} \theta+\frac{Q}{\rho C}=\frac{\mathrm{D} \theta}{\mathrm{D} t}
$$

where $\kappa$ is the thermal diffusivity of ice, $Q$ is the internal heat generation, $\rho$ is the ice density, and $C$ is the heat capacity. To obtain a solution to this equation, boundary conditions at the surface and bed must be known. The boundary condition at the bed is generally taken to be the temperature gradient in the ice required to conduct the geothermal heat upward into the glacier, with certain modifications where the pressure melting temperature is reached. The boundary condition at the surface is the ice temperature, which is usually assumed to be equal to the mean annual atmospheric temperature. This assumption is incorrect in the ablation area and in the percolation and saturation zones of the accumulation area. In this paper I examine the reasons for the break down of this assumption, and attempt to indicate the magnitude of the error introduced. 